\title{
Changes Induced by Physical Activity, Weight Loss and Calorie Restriction in Body Composition, Lipoproteins and Functional Capacity in Obese Congolese Women
}

\author{
Moulongo Jean Georges André1 ${ }^{*}$, Makosso Vheiye Georges ${ }^{2}$, Eouani Max Lévy Eméry3, \\ Mouanda Richard Le Savant ${ }^{4}$, Ndalla Mathias Cyriaque ${ }^{5}$, Packa Tchissambou Bernard1, \\ Massamba Alphonse ${ }^{1,6}$
}

\author{
${ }^{1}$ Laboratory of Sports Biosciences, Higher Institute of Physical Education and Sports, Marien NGOUABI University, Brazzaville, \\ Congo \\ ${ }^{2}$ Unit of Nutritional Science and Metabolism, Higher Institute of Physical Education and Sports, Marien NGOUABI University, \\ Brazzaville, Congo \\ ${ }^{3}$ Department of Gynecology \& Obstetrics, Loandjili Hospital, Pointe-Noire (Congo) and Faculty of Health Sciences, Marien \\ NGOUABI University, Brazzaville, Congo \\ ${ }^{4}$ Clinical Psychology Research Division, Marien NGOUABI University, Brazzaville, Congo \\ ${ }^{5}$ Biomedical Analyses Center, Makelekele, Brazzaville, Congo \\ ${ }^{6}$ Laboratory of Numerical Analysis, Computer Science and Applications, Faculty of Sciences and Technology, Marien NGOUABI \\ University, Brazzaville, Congo \\ Email: *jgamoulongo@gmail.com
}

How to cite this paper: André, M.J.G., Georges, M.V., Eméry, E.M.L., Le Savant, M.R., Cyriaque, N.M., Bernard, P.T. and Alphonse, M. (2020) Changes Induced by Physical Activity, Weight Loss and Calorie Restriction in Body Composition, Lipoproteins and Functional Capacity in Obese Congolese Women. Health, 12, 548-571. https://doi.org/10.4236/health.2020.126043

Received: March 28, 2020

Accepted: June 5, 2020

Published: June 8, 2020

Copyright $\odot 2020$ by author(s) and Scientific Research Publishing Inc. This work is licensed under the Creative Commons Attribution International License (CC BY 4.0).

http://creativecommons.org/licenses/by/4.0/ (c) (i) Open Access

\begin{abstract}
Background. The effects of physical exercises combined with a low-calorie diet on weight loss, body composition, lipoproteins profile, and physical fitness had been well described. However, Central Africa's studies investigating these kinds of diets and exercise regimens are lacking. Objective. To investigate the effects of adding 14-weeks exercises to a hypocaloric diet on changes in body composition, lipoproteins concentrations, and physical capacities in obese Congolese women. Population and Methods. In total, 34 obese women aged 30 - 39 years (mean age: $33.7 \pm 2.4$ years) assigned to 14 -weeks training program and low energy ketogenic diet. Body composition was assessed using classic methods and impedancemetry. Fasting plasma glucose (FPG) and fasting serum insulin were assessing using enzymatic colorimetric and radioimmunoradiometric methods. HOMA-IR and lipoproteins concentrations were assessed using standardized laboratory methods. $\mathrm{VO}_{2 \text { peak }}$ was measured on a treadmill during a progressive exercise test. Speed, cadence and stride length were measured along the $10-\mathrm{m}$ level walkway. Muscular endurance was measured using the tests of sit-up and inflections-extensions of el-
\end{abstract}


bows. All the variables of the study were assessed at the beginning, in the 7-weeks, and in the 14-weeks of training methods. Results. Declines in body weight (16\%), percent fat (12.1\%), fat weight $(26.4 \%)$, abdominal fat $(34.2 \%)$, and waist circumference (10.4\%) were found. A significant decrease in FPG (13\%), fasting serum insulin (60.9\%), HOMA-IR (64.7\%), total cholesterol (12.2\%), LDL-cholesterol (20.3\%), triglycerides (92.8\%), and VLDL-triglycerides (17.5\%) was shown. In contrast, significant increase in HDL-cholesterol (27.13\%) was found. The peak oxygen consumption $\mathrm{VO}_{2 \text { peak }}$ relative to body weight improved more in the 14-weeks training program (13.4\%). Obese women exhibited higher values in the 14-weeks training program for speed gait $(16.5 \%)$, cadence $(9.1 \%)$, and stride length $(15.7 \%)$ during normal walk and rapid walk. Weight loss combined with a low-calorie diet and 14-weeks training program improved significantly muscular endurance capacities. Conclusion. Exercise added to hypocaloric diet leads to decreases in body composition, to improve in insulin sensitivity, to enhancement of $\mathrm{VO}_{2 \text { peak }}$ and functional fitness. This may be helpful for the treatment of the metabolic complications of abdominal obesity.

\section{Keywords}

Lipoproteins, Body Composition, Calorie Restriction, Physical Exercise, Obese Congolese Women

\section{Introduction}

Overweight and obesity in the countries with low or medium incomes are becoming nowadays a serious public health problem, particularly in urban environment [1] [2] [3]. It is the case of the countries of sub-Saharan Africa where obesity is often socially developed. For example, in Mauritania young women in age to marry are fattened in order to be tempting and to maximize their chance to find a spouse [4]. They are especially the women resulting from the easy social layers, where obesity is regarded as success and of richness signs. This observation is also found in Congo where the prevalence of obesity in woman is 50.9\% in 2016 versus $45.9 \%$ in 2011 [3]. However, owing to the fact that obesity is a factor of major risk of cardiovascular diseases, type 2 diabetes mellitus and associated comorbidities [5] [6] [7], several studies have also identified various negative consequences of obesity such alterations of skeletal muscle and insulin signaling pathways [8], a gait alterations [9] [10], posture deficits [11] [12] and great risk of falling [13]. In addition, obesity is associated with functional decline [14], altered spatiotemporal gait parameters (e.g. lower gait speed, shorter strides, and increased step width) [9] [15]; obesity also negatively affects balance control [12] [16].

It is to mitigate these dysfunctions that several of active Congolese young people in the professional life and of age often lower than 45 years, after 5 years of marriage or common life choose a voluntary weight loss, moved by aesthetic 
reasons. This weight loss, rather progressive, is spread out over one period from 5 to 15 weeks. For that, the women practice physical activities by jogging, exercises of aerobic gymnastics and muscular reinforcements for $270 \mathrm{~min} / \mathrm{wk}$, in sessions of $\geq 45 \mathrm{~min}$. Concurrently to this program, they are essential food restrictions translated into lipid and hydrous intakes reduction, restrictions more significant than those of carbohydrates and protein intakes. All things considered, weight loss due to the adopted strategy oscillates between rapid weight loss and progressive weight loss; thus it does not obey the recommendations listed in the literature. Indeed, the American College of Sports Medicine recommended 200 $300 \mathrm{~min} / \mathrm{wk}$. However, current practice guidelines include recommendations that physical activity could be undertaken for $30 \mathrm{~min} / \mathrm{d}$ for most days of the week, increasing, when appropriate, to $60 \mathrm{~min} / \mathrm{d}$ [17]. The adoption of this strategy in Congo is explained mainly by the lack of health professionals qualified in adapted physical activities. It is in this context that we initiated this study in order to determine the combined effects of a demanding 3-month period of dietary energy restriction and regular exercises on body composition, plasma lipoproteins and physical function in obese young adult Congolese women. We hypothesized that 1) quality and quantities of aliments taken during training program represents major indicators of a low-calorie diet, 2) aerobic endurance race, aerobic gymnastics and muscular reinforcements are able to decrease to their body mass by decreasing fat mass and increasing lean body mass, 3) aerobic exercise and muscular reinforcements of 3-month duration and dietary restriction are associated with substantial improvements in plasma lipoprotein levels, and that 4) physical fitness is increased. The interest of this study is to provide relevant information to the executives of physical activities, and with the health professionals in sub-Saharan Black Africa for understand the many physiological and environmental factors influencing body weight and energy balance, and to improve their ability to design individualized and realistic weight management programs.

\section{Population and Methods}

\subsection{Study Design}

The study was initiated by the Laboratory of Sport Biosciences and the Laboratory "Health and Adapted Physical Activities" of the Higher Institute of Physical Education and Sports. The sample size was based on the data of the WHO [3] devoted to the prevalence of overweight and obesity among active women of Brazzaville, old from 20 - 50 years. Thus, healthy obese and premenopausal women were selected between March 32019 and June 182019 (14 weeks) from women attending one fitness club in Brazzaville, Congo, to lose weight.

This private fitness club, one of 34 fitness clubs (private and public) in capital city of Brazzaville and the surrounding areas that uses an integrated approach (dietary, behavioral, and exercise) for weight loss in women, was selected through local advertisement (Figure 1). The club is based on helping each member 


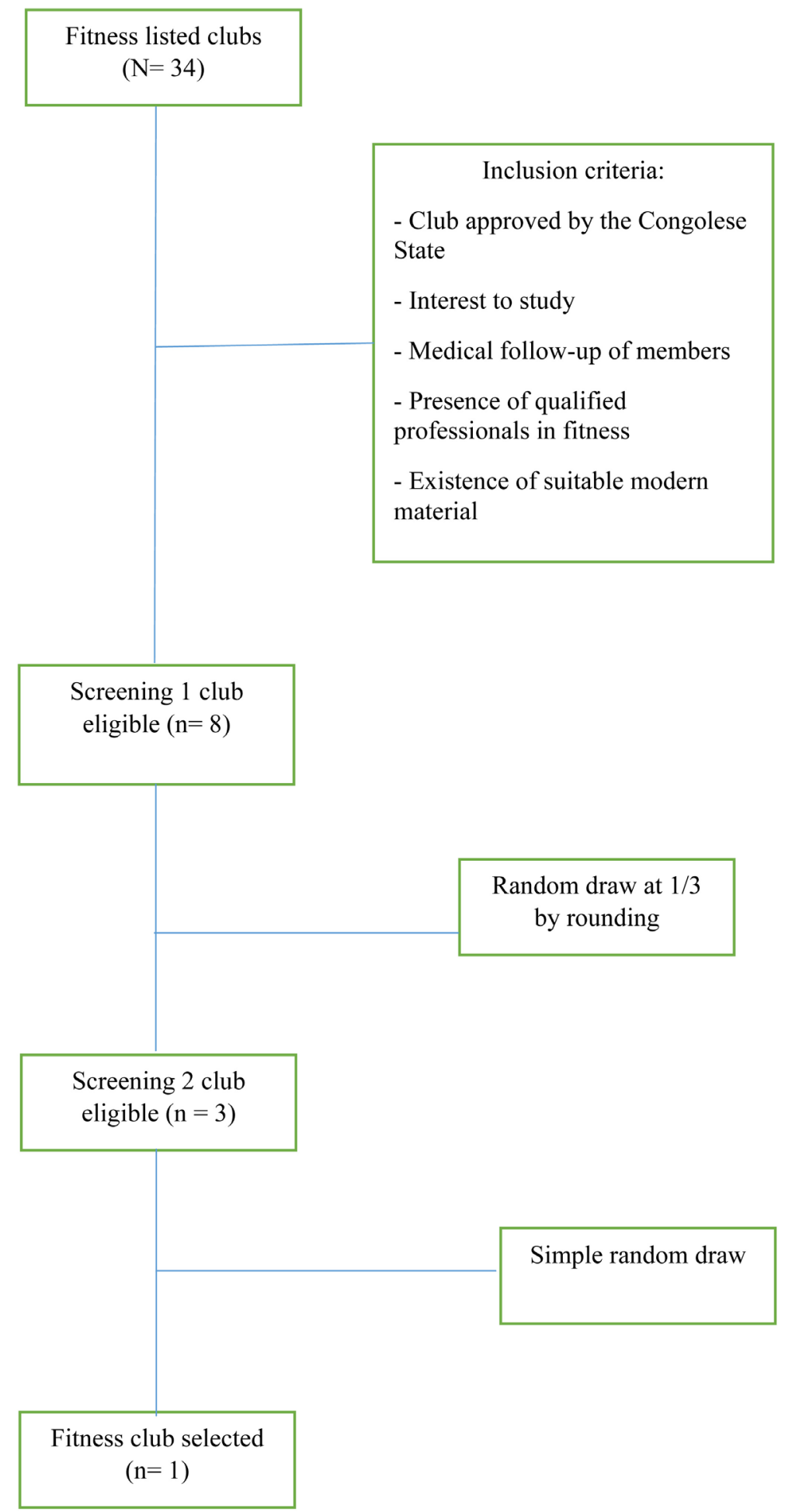

Figure 1. Fitness club recruitment process.

developed his or her own problem solving approach. The initial program was designed weight loss of $7 \%-15 \%$ of initial body weight at the rate of $0.5-1$ $\mathrm{kg} /$ week over 24 weeks, and conformed on the recommendations of American College of Sports Medicine [18]. 


\subsection{Participants}

Of 52 women who were interested in participating in the study, a total of 34 healthy women aged 30 - 39 years-old (mean age: $33.7 \pm 2.4$ years) from the city of Brazzaville were enrolled based on the following criteria: aged 30 - 45 years, BMI: 30 - $39 \mathrm{~kg} / \mathrm{m}^{2}$, sedentary lifestyle (reported exercising $<3$ days/week for $<20$ min per day for previous 6 months) and willing to introduce dietary changes to weight loss during 14 weeks. Exclusion criteria were: to be smoker, pregnancy or lactation during the 6 months or planning a pregnancy in the next 6 months, stroke, diabetes, liver or kidney disease, pulmonary dysfunction, musculoskeletal or neuromuscular impairments that preclude exercise training, autoimmune depression, cancer, and disease, taking antimalaria medication in the past one month that could affect oxygen blood transport, taking medication to lower lipids or cholesterol or medication that could affect metabolism or changes body weight (except thyroid medication, statin therapy, but oral hypoglycemic medication).

Participants followed a food regimen with food restrictions (lipids and hydrous) for a weight loss ranging between $10 \%-20 \%$ of body weight from recruitment on the study. Lifestyle data and clinical characteristics of subjects are presented in Table 1.

Table 1. Baseline characteristics of subjects.

\begin{tabular}{|c|c|c|}
\hline Characteristic & $\mathrm{n}$ & $\%$ \\
\hline \multicolumn{3}{|c|}{ Race } \\
\hline Black Congolese & 28 & 82.4 \\
\hline Other black African & 6 & 17.6 \\
\hline \multicolumn{3}{|c|}{ Education } \\
\hline Less than college degree & 9 & 26.5 \\
\hline College degree & 15 & 44.1 \\
\hline Graduate school & 10 & 29.4 \\
\hline \multicolumn{3}{|c|}{ Maritus status } \\
\hline Single & 6 & 17.6 \\
\hline Married & 24 & 70.6 \\
\hline Widowed & 4 & 11.8 \\
\hline \multicolumn{3}{|c|}{ Alcohol consumption (per week) } \\
\hline Never & 8 & 23.6 \\
\hline Sometimes ( $1-2$ times) & 20 & 58.8 \\
\hline Daily & 6 & 17.6 \\
\hline \multicolumn{3}{|c|}{ Blood pressure (mean \pm SD) } \\
\hline SBP (mmHg) & $120 \pm 12$ & \\
\hline $\mathrm{DBP}(\mathrm{mmHg})$ & $76 \pm 15$ & \\
\hline $\mathrm{PP}(\mathrm{mmHg})$ & $45 \pm 10$ & \\
\hline $\mathrm{HR}(\mathrm{b} / \mathrm{min})$ & $80 \pm 9$ & \\
\hline
\end{tabular}

Abbreviations: SBP, systolic blood pressure; DBP, diastolic blood pressure; PP, pulse pressure; HR, heart rate. 
The study was approved by the National Ethical Commitee on Health Sciences Research, Congolese Delegation of Scientific and Technological Research (Agreement APA-DB-015). All participants were given comprehensive explanations regarding the study design, protocols, and possible risks, and informed consent in accordance with the Declaration of Helsinki.

\subsection{Physical Training}

The training frequency, intensity and volume were calculated from the diaries. The intensity of the exercise was calculated using the equation of Karvonen according to the cardiac capacity of reserve. Split routines were used for muscular reinforcements that they focused on single muscle groups per session as is often the case also in the Congolese study of Kusuayi et al. [19]. The training program comprised 4 sessions per week of one hour thirty minutes in duration each one, that is to say 360 minutes/week and a total 5040 minutes (360 min $\times 14$ weeks) for all the duration of training program. During one week, the first and the fourth week were devoted to the jogging and the aerobic training. The second was reserved for the reinforcement of muscular groups particularly thighs, hamstrings, buttocks, check, shoulders, arms, upper and lower back, calves, and abdominal. The third session as for it gathered the three quoted activities (jogging + aerobic training + muscular reinforcements). Aerobic training for all participating was almost uniquely either exercises of aerobic gymnastics, moderate or high-intensity interval training (HIT) with bicycle, crosstrainer, but other gym equipment or both HIT and steady-state low to medium intensity aerobics (usually walking/running or with crosstrainer). Typical HIT-exercise and aerobic gymnastics was $65-70 \mathrm{~min}$ in total including high intensity $15-45 \mathrm{~s}$ intervals with $30-60 \mathrm{~s}$ of recovery between the sets. Steady state lower intensity aerobics was typically 30 - $60 \mathrm{~min}$ in duration.

To encourage the participating to achieve the request program goal, their treatment included encouragement to recruit a partner from their group of friends and family members to participate in the activity part of the study with them. The activities carried out during the program were at moderate intensity (60\% - 70\% theoretical HRmax) during the first seven weeks, high intensity (80\% - 90\% HR max) in the $7^{\text {th }}$ to the $14^{\text {th }}$ week.

\subsection{Dietary Strategy}

All the women included in the study interviewed by a dietitian who evaluated their food preferences and their intakes, as well as a compliance test to dietetic regimen over 7 days. Then, the energy needs for each participating were establish by a dietitian. Energy intake was based on the individual calculated basal metabolic rate according to the Harris-Benedict equation, multiplied by 1.5. The recourse to a dietitian of the Laboratory of Sport Biosciences made it possible to assist the subjects in assessing the portion/amount of consumed food. For that, quantification tools such have household measures and graduated food models 
were used. The method of recall of consumed food during the 24 last hours and the table of food composition of African foods synthesizing several sources [20] and improved compared to those already used in Congo [21] and in Europe [22] made it possible to determine the daily intakes in various foods, and then translated into nutrients. This process made it possible to evaluate the average daily energy intakes $(1 \mathrm{kcal}=4.18 \mathrm{~kJ})$, the percentage of energy provided respectively by the proteins, lipids and carbohydrates, and the fiber intakes. A vitamin and mineral tablet were taken on risin and before bed. The composition of all the meals (midday and evening) was prepared and provided. All participants observed 30\% restrict energy intake, according to the recommendations of coach's club which was based on the results of the study of Redman et al. [23]. The goal of adopted hypocalorie regimen being to obtain in the whole group a calorie deficit of $400 \mathrm{kcal}$ per day, the participants were to supplement a log book and to bring back to their food consumption during the 24 last hours each day. This filled out newspaper was re-examined by the dietitian each day.

The individual diet program was based on the participant's food diary records, which reflected their food preferences. For that, each subject signed a weekly declaration of adherence of the diet. All subjects were encouraged to drink at least 1.5 liters of water daily. Coffee, tea of other beverages were not permitted.

\subsection{Measurements}

Anthropometric, haemodynamic, haematological and physical capacities measurements were taken at baseline, in the 7-weeks and 14-weeks of training program.

\section{Anthropometric Measurements}

Body weight was measured to the nearest $0.1 \mathrm{~kg}$ using a digital calibrated scale (Omron Health Care) while the participants were light clothing, with no shoes. Body height was measured to the nearest $0.1 \mathrm{~cm}$ by using a Seca portable height measure (Seca Ltd., Hambourg, Germany) without shoes, and with participants in a free-standing position. Body mass index (BMI) was calculated using the formula: Weight $(\mathrm{kg}) /[\text { Height }(\mathrm{m})]^{2}$. Waist circumference (WC, minimal circumference) was measured with a rigid measuring tape and recorded to the nearest $0.5 \mathrm{~cm}$. WC was measured at the smallest horizontal circumference between the ribs and iliac crest (the natural waist), or, in case of an indeterminable waist narrowing, halfway between the lower rib and the iliac crest [24]. Hip (maximal gluteal protuberance) was measured in triplicate. Waist-to-hip ratio (WHR) was also calculated. Total body fat and abdominal visceral fat were measured using a 4-electrodes segmental 3-frequencies (5, 50 and $100 \mathrm{kHz})$ bioelectrical impedance (Analycor, Eugedia-Spingler, France). These measurements were taken on each participant at rest in reclining position. Two electrodes of surface are placed at the wrist (radial and cubital styloïde). Two electrodes are on the level of ankle (tibial malleolus) and end of the second metatarsal. The collection of the data related to the lean body mass by making the sum of weights of hydrous compartments by the product of densities by volumes of each extracel- 
lular and intracellular compartment [25].

\section{Blood Pressure Data}

After 5 minutes relaxation, seated blood pressure (BP) was measured at the left arm from each subject with the help of an Omron M1 digital electronic blood pressure/pulse monitor (Omron Corporation, Tokyo, Japan); three BP measurements were taken and averaged for analysis.

\section{Blood Sampling}

Fasting plasma glucose (FPG) concentrations were measured with the use of the enzymatic colorimetric method, with intra-and interassay CVs $<2 \%$. Insulin was measured by using radioimmunoassay with 125I-labeled human insulin and a human insulin antiserum in an immunoradiometric assay (Biosource) with a $\gamma$-counter system (Gamma I, Genesys), with intra-and interassay CVs $<2.3 \%$. Homeostatic model assessment of insulin resistance (HOMA-IR) values were calculated using the Homa calculator, version 2.2, software (Diabetes Trial Unit, University of Oxford). The software was downloaded from http://www.dtu.ox.ac.uk/homa.

\section{Lipoprotein Lipids}

Blood samples were collected in EDTA-treated evacuated tube by venipuncture in the early morning after a 12-h fast on duplicate testing days both before, in 7 weeks and after 14 weeks the intervention. The values reported of the average of 2 measurements. Plasma triglycerides (TG), VLDL-triglycerides, total cholesterol (TC), HDL-cholesterol, and LDL-cholesterol were measured by standardized hospital laboratory methods.

\subsection{Physical Fitness}

A verbal and practical explanation of the tests of physical condition was initially carried out. Thereafter, the evaluated parameters were:

- Aerobic capacity or maximum consumption of oxygen $\left(\mathrm{VO}_{\text {2peak }}\right) . \mathrm{VO}_{2 \text { peak }}$ was measured program on a treadmill (Medical Graphics Corporation, Minneapolis, MN) during a progressive exercise test to voluntary exhaustion. A ramp treadmill protocol was used: the speed was set at a constant rate according to individual ability, and the inclines increased at small intervals continuously throughout the test [26]. A valid $\mathrm{VO}_{2 \text { peak }}$ was obtained when at least 2 of the 3 criteria were met: 1) plateau in $\mathrm{VO}_{2}(<200 \mathrm{ml} / \mathrm{min}$ change) with increasing work misses; 2) maximum heart misses (HR max $>90 \%$ of age - predicted HR max, 220 beats/min-age), and 3 ) respiratory exchange ratio of $\geq 1.10$. If the participant did not reach these criteria, the test was repeated.

- Gait. Women walked twice along the 10-m level walkway at a comfortable speed and twice at a fast speed [27]. Gait was recorded at $100 \mathrm{~Hz}$ using a 12 cameras $(\mathrm{Mx} 3+$ model) motion capture system (Vicon, Oxford Metrics, Oxford, UK). Reflective spherical markers were placed at the heel, and the second metatarsal joint. Foot contact and foot-off events were recorded at $100 \mathrm{~Hz}$ with synchronized footswitches (Aurion, Zerowire, IT), placed at the 
heel and at the head of the first metatarsal head. Spatiotemporal gait parameters (speed, cadence, stride length) were extracted with a custom program in Mathlab R2008 (The Math Works, Natick, USA). Fast gait speed was determined by a measurement of the time needed to walk $25 \mathrm{ft}$.

- The muscular endurance, using the tests of sit-up and inflections-extensions of elbows (IEE) from the Eurofit battery's tests of evaluation of physical fitness.

\subsection{Operational Definitions}

Visceral fat was defined as fat enclosed by the inner aspect of the abdominal wall [28].

Hypertensive was defined as $\mathrm{BP} \geq 140 / 90 \mathrm{mmHg}$ or current use of antihypertensive drugs [29].

Women were defined as premenopausal if they had had an unchanged and regular menstrual pattern [30].

Depression as defined by Beck's Depression Inventory [31].

\subsection{Statistical Analysis}

All the variables of the study (except food intake dated) were evaluated at the beginning of the program $\mathrm{T}(0)$, at the end of the $7^{\text {th }}$ week $\left(\mathrm{T}_{7_{\text {week }}}\right)$ and the $14^{\text {th }}$ week ( $\mathrm{T}_{14 \text { week }}$ ) of physical training. Statistical software IBM SPSS for Windows 22.0 (Armenk NY, 2013) was used for statistical analyses. All data are expressed as means (value or percentage) $\pm \mathrm{SD}$. Normality, skewness and possible outliers were checked with the Shapiro-Wilk test. Data were analyzed with the repeated measured one way ANOVA (time $\times$ group) to compare the values obtained on each parameter during various measurements. When this one was significant, the test post hoc of Tukey was carried out for localize the difference. Sokal S test was used as appropriate for 3 percentages comparisons. Student $t$ test was used for comparing two means. Additionally, a Pearson's two-tailed correlation and linear regression analyses were performed between weight, body fat parameters and $\mathrm{VO}_{2 \text { peak. }} \mathrm{p}<0.05$ defined the level of statistical significance.

\section{Results}

\subsection{Dietary Characteristics}

The principal characteristics of the energy intakes, calorie restrictions and energy expenditure of exercise are reported in Table 2.

The daily energy intakes of women in the 7- to 14-weeks training program were higher than those noted in the 0- to 7-weeks training program, but no significant difference: $1853 \pm 401 \mathrm{kcal} / \mathrm{d}$ versus $1705 \pm 490 \mathrm{kcal} / \mathrm{d}$. However, it was observed an increase of $148 \mathrm{kcal}(\Delta=+8.7 \%)$ between $\mathrm{T}\left({ }_{0}\right)-\mathrm{T}\left(7_{\text {weeks }}\right)$ and $\mathrm{T}\left(7_{\text {weeks }}\right)$ - $\mathrm{T}\left({ }_{14 \text { weeks }}\right)$. The report was similar for the energy expenditure of exercise: $646 \pm$ $200 \mathrm{kcal} / \mathrm{wk}$ versus $751 \pm 210 \mathrm{kcal} / \mathrm{wk}$ ( $\mathrm{p}>0.05)$, with increase of $105 \mathrm{kcal}(+16.3 \%)$. In addition, no significant difference for lipid and carbohydrates intakes between 
Table 2. Self-reported dietary intake.

\begin{tabular}{|c|c|}
\hline Energy intakes with inclusion (kcal/d) & $1770 \pm 445$ \\
\hline \multicolumn{2}{|c|}{$\mathrm{T}(0)-\mathrm{T}\left(7_{\text {week }}\right):$ moderate physical activity } \\
\hline Calorie restriction $(\mathrm{kcal} / \mathrm{d})$ & $340 \pm 88$ \\
\hline Total energy $(\mathrm{kcal} / \mathrm{d})$ & $1705 \pm 490$ \\
\hline Protein $(g)$ & $71.3 \pm 8.6$ \\
\hline Protein (\%) & $15.4 \pm 1.5$ \\
\hline Fat $(g)$ & $61.3 \pm 9.1$ \\
\hline Fat $(\%)$ & $30.4 \pm 1.9$ \\
\hline Carbohydrate (g) & $245.2 \pm 24$ \\
\hline Carbohydrate (\%) & $56.4 \pm 1.3$ \\
\hline Fiber (g) & $23.1 \pm 2.2$ \\
\hline Energy expenditure of exercise (kcal/wk) & $751 \pm 210$ \\
\hline \multicolumn{2}{|c|}{$T(7$ week $)-T(14$ week $)$ : intense physical activity } \\
\hline Calorie restriction $(\mathrm{kcal} / \mathrm{d})$ & $302 \pm 74$ \\
\hline Total energy (kcal) & $1853 \pm 401$ \\
\hline Protein $(g)$ & $77.6 \pm 5.2^{\mathrm{a}}$ \\
\hline Protein $(\%)$ & $16.7 \pm 1.8$ \\
\hline Fat $(\mathrm{g})$ & $65.4 \pm 7.5$ \\
\hline Fat $(\%)$ & $32.3 \pm 1.9$ \\
\hline Carbohydrate (g) & $256.4 \pm 23.7$ \\
\hline Carbohydrate (\%) & $50.9 \pm 2.2$ \\
\hline Fiber $(\mathrm{g})$ & $22.1 \pm 3.6^{\mathrm{b}}$ \\
\hline Energy expenditure of exercise (kcal/wk) & $751 \pm 210$ \\
\hline
\end{tabular}

a: $\mathrm{p}<0.05$ for protein intakes; ${ }^{\mathrm{b}}$ : $\mathrm{p}<0.01$ for fiber intakes.

the two periods of training was found. However, the fiber intakes were higher at intensive period of training: $28.3 \pm 3.6 \mathrm{~g}$ versus $23.1 \pm 2.2 \mathrm{~g}(\mathrm{p}<0.01)$.

\subsection{Body Composition}

The initial characteristics of women, and their changes during 3-month training program are shown in Table 3.

The subjects had a total weight loss of $12.2 \pm 5.6 \mathrm{~kg}$ (range: $6.3-21.2$ ), representing a $16 \%$ reduction from the baseline body weight with a more rapid decline in the second period of training than the first. Also, the weight loss in the 0 - to 7-weeks period of training was significantly higher in the 7- to 14 -weeks period both expressed in kilograms $(7.5 \pm 4.3 \mathrm{~kg}$ vs. $4.7 \pm 2.1 \mathrm{~kg})$ and in percentages from the baseline level $(9.6 \% \pm 2.1 \%$ vs. $5.5 \pm 1.3 \%)$.

Almost all women, the weight loss mass was accompanied by a BMI and TFM reduction, respectively of $4.5 \pm 2.4 \mathrm{~kg} / \mathrm{m}^{2}$ (range: $0.9-7.2$ ) and $8.2 \pm 4.3 \mathrm{~kg}$ 
Table 3. Changes of body composition characteristics of women during 14 weeks training program.

\begin{tabular}{|c|c|c|c|c|c|}
\hline Parameters & $\mathrm{T}(0)$ & $\mathrm{T}$ (7weeks) & $T(14$ weeks $)$ & $\%$ change & F or $S$ value; $p$ \\
\hline \multicolumn{6}{|c|}{ Body composition } \\
\hline Height $(\mathrm{cm})$ & $165.9 \pm 5.9$ & - & - & - & - \\
\hline Weight (kg) & $90.4 \pm 6.6$ & $85.7 \pm 8.3$ & $78.2 \pm 6.1$ & -16.0 & $8.09 ;<0.01$ \\
\hline BMI $\left(\mathrm{kg} / \mathrm{m}^{2}\right)$ & $33.5 \pm 3.5$ & $31.5 \pm 2.2$ & $29.0 \pm 1.4$ & -15.5 & $8.52 ;<0.01$ \\
\hline TFM (kg) & $39.3 \pm 5.2$ & $36.9 \pm 4.5$ & $31.1 \pm 2.8$ & -26.4 & $9.02 ;<0.001$ \\
\hline TLBM (kg) & $52.7 \pm 4.8$ & $53.3 \pm 5.0$ & $53.8 \pm 4.3$ & +2.1 & $0.15 ;>0.05$ \\
\hline Body fat (\%) & $42.7 \pm 3.3$ & $40.6 \pm 2.3$ & $38.1 \pm 1.1$ & -12.1 & $6.27 ;<0.01$ \\
\hline \multicolumn{6}{|c|}{ Fat distribution } \\
\hline $\mathrm{WC}(\mathrm{cm})$ & $98.5 \pm 8.6$ & $94.3 \pm 5.4$ & $89.2 \pm 3.6$ & -10.4 & $5.87 ;<0.01$ \\
\hline $\mathrm{HC}(\mathrm{cm})$ & $119.2 \pm 8.5$ & $113.6 \pm 6.2$ & $109.1 \pm 3.9$ & -9.2 & $5.92 ;<0.01$ \\
\hline WHR & $0.83 \pm 0.08$ & $0.83 \pm 0.04$ & $0.82 \pm 0.04$ & -1.2 & $0.11 ;>0.05$ \\
\hline AV fat (\%) & $11.72 \pm 1.84$ & $9.25 \pm 1.07$ & $8.73 \pm 1.85$ & -34.2 & $19.45 ;<0.001$ \\
\hline
\end{tabular}

Abbreviations: BMI, body mass index; TFM, total fat mass; TLBM, total lean body mass; WC, waist circumference; HC, hip circumference; WHR, waist-hip ratio; AV fat, abdominal visceral fat.

(range: 3.6 - 13.4). The decrease of TFM was also more marked during $\mathrm{T}\left(7_{\text {weeks }}\right)$ $\mathrm{T}\left({ }_{14 \text { weeks }}\right)$ period: $18.6 \% \pm 2.1 \%$ vs. $6.5 \% \pm 1.7 \%(\mathrm{p}<0.01)$. The mean percentage of body fat showed the same trend as TFM, with a low increase in the second period of training program: $6.5 \%$ vs. $5.2 \%$. TLBM showed a total increase of $1.1 \pm$ $0.3 \mathrm{~kg}(1.1 \% \pm 0.5 \%$ in the 0 - to 7 -weeks period; $0.9 \% \pm 0.4 \%$ in the 7 - to 14-weeks period).

The mean values of fat distribution showed significant decreases in waist $[\mathrm{F}(2$, $31)=5.87, \mathrm{p}<0.01]$ and hip girths $[\mathrm{F}(2,31)=5.92, \mathrm{p}<0.01]$, as well as abdominal visceral fat $(\mathrm{p}<0.001)$. The values noted in the 7 - to 14 -weeks period were higher than those in 0 - to 7 -weeks period (except to $\mathrm{HC}$ ), with respectively rates of: $5.7 \%$ vs. $4.4 \%$ (WC) and $17.4 \%$ vs. $14.3 \%$ (AVfat).

\subsection{Changes of Plasma Lipoprotein Concentrations}

Changes of plasma lipoprotein concentrations for all women from baseline to 14 weeks of training program are shown in Table 4.

The weight loss during training program associated to calorie restriction dietary resulted in significant decreases in fasting plasma glucose $[\mathrm{F}(2,31)=4.9, \mathrm{p}$ $<0.05]$ and fasting plasma insulin $[\mathrm{F}(2,31)=3.80, \mathrm{p}<0.05]$, thus improving insulin sensitivity estimated with the HOMA-IR index $(-64.7 \%$; $\mathrm{p}<0.001)$. This improvement was accentuated in the 7- to 14 -weeks period than in the 0 - to 7-weeks period: $32.3 \% \pm 5.1 \%$ versus $24.4 \% \pm 8.2 \%$. Positive change increases in HDL-cholesterol concentrations were observed during training program, expressed in percentages from the baseline: $+3.9 \%$ in the 0 - to 7 -weeks period and $7.0 \%$ in the 7- to 14 -weeks period. In contrast, total cholesterol and LDL-cholesterol 
Table 4. Pre, mid and post-regimen values for selected lipoproteins variables.

\begin{tabular}{cccccc}
\hline Parameters & $\mathrm{T}(0)$ & $\mathrm{T}\left(7_{\text {weeks }}\right)$ & $\mathrm{T}\left({ }_{14 \text { weeks }}\right)$ & \% change & $\mathrm{F}$ or $\mathrm{S}$ value; $\mathrm{p}$ \\
\hline FPG $(\mathrm{mmol} / \mathrm{l})$ & $6.2 \pm 0.8$ & $5.8 \pm 0.5$ & $5.5 \pm 0.3$ & -13.0 & $4.09 ;<0.05$ \\
FSI $(\mu \mathrm{IU} / \mathrm{ml})$ & $14.0 \pm 2.1$ & $11.5 \pm 1.2$ & $8.7 \pm 1.6$ & -60.9 & $3.80 ;<0.05$ \\
HOMA-IR & $1.12 \pm 0.09$ & $0.90 \pm 0.11$ & $0.68 \pm 0.06$ & -64.7 & $65.04 ;<0.001$ \\
TC $(\mathrm{mmol} / \mathrm{l})$ & $5.29 \pm 0.18$ & $5.11 \pm 0.22$ & $4.71 \pm 0.18$ & -12.2 & $24.87 ;<0.001$ \\
HDL-cholesterol $(\mathrm{mmol} / \mathrm{l})$ & $1.29 \pm 0.04$ & $1.31 \pm 0.05$ & $1.41 \pm 0.02$ & +9.3 & $27.13 ;<0.001$ \\
LDL-cholesterol $(\mathrm{mmol} / \mathrm{l})$ & $3.68 \pm 0.59$ & $3.47 \pm 0.35$ & $3.06 \pm 0.47$ & -20.3 & $4.59 ;<0.05$ \\
TG $(\mathrm{mmol} / \mathrm{l})$ & $1.62 \pm 0.42$ & $1.38 \pm 0.36$ & $0.84 \pm 0.31$ & -92.8 & $10.20 ;<0.001$ \\
VLDL-TG (mmol/l) & $1.41 \pm 0.25$ & $1.35 \pm 0.11$ & $1.20 \pm 0.13$ & -17.5 & $4.08 ;<0.05$ \\
\hline
\end{tabular}

Abbreviations: HDL, high density lipoprotein; LDL, low density lipoprotein; TG, triglycerides; VLDL-TG, very low density lipoprotein of triglycerides; FPG, fasting plasma glucose; FSI, fasting serum insulin; TC, total cholesterol.

concentrations decreased, representing respectively a $12.2 \%$ and $20.3 \%$ reduction. ANOVA revealed higher decreases in triglycerides concentrations, $-92.8 \%$ $[\mathrm{F}(2,31)=10.20, \mathrm{p}<0.001]$ and VLDL-triglycerides concentrations, $-17.5 \%$ $[\mathrm{F}(2,31)=4.08, \mathrm{p}<0.05]$; differences were also founded in the 7 to 14 -weeks period: $28.6 \%$ vs. $22.2 \%$ and $12.5 \%$ vs. $4.4 \%$.

\subsection{Changes of Physical Capacities}

The mean $( \pm S D)$ scores on the physical performance tests are reported in Table 5.

Measurements of $\mathrm{VO}_{2 \text { peak }}$ at baseline, after 7 weeks and 14 weeks training program, expressed as $\mathrm{ml} / \mathrm{kg} / \mathrm{min}, 1 / \mathrm{min}$ and $\mathrm{ml} / \mathrm{kg} \mathrm{LBM} / \mathrm{min}$ showed increases at 14 weeks of $13.4 \%, 8.0 \%$, and $15.5 \%$ respectively. Comparisons among $\left.\mathrm{T}_{0}\right)$ $\mathrm{T}\left(7_{\text {weeks }}\right)$ and $\mathrm{T}\left(7_{\text {weeks }}\right)-\mathrm{T}\left({ }_{14 \text { weeks }}\right)$ showed higher percentage increases for $\mathrm{T}\left(7_{\text {weeks }}\right)$ $\mathrm{T}(14$ weeks $)$, respectively $12.1 \%$ vs. $6.8 \%(\mathrm{p}<0.05), 3.9 \%$ vs. $3.8 \%(\mathrm{p}<0.05)$, and 9.1\% vs. $5.9 \%(\mathrm{p}<0.05)$.

Concerning spatiotemporal gait parameters, speed data of walk increases during training program of $5.4 \%$, higher rates being founded in the 7 - to 14-weeks period: $3.2 \%$ versus $2.1 \%(\mathrm{p}<0.05)$ from baseline data. The normal walking speed, cadence and stride length increased significantly during training program, 15.9\% $[\mathrm{F}(2,31)=17.02, \mathrm{p}<0.001], 9.1 \%[\mathrm{~F}(2,31)=6.43, \mathrm{p}<0.01]$, and $13.6 \%[\mathrm{~F}(2,31)=11.99, \mathrm{p}<0.001]$, respectively. The fast walking speed was already significantly increased at 14 weeks of training program $(+17.2 \%$; $\mathrm{p}<$ $0.05)$. Cadence and stride length continued also to increase, $+9.2 \%(\mathrm{p}<0.05)$ and $+17.2 \%(\mathrm{p}<0.01)$ respectively.

We evaluate positive changes two components (abdominal muscles and arm muscles) of muscular endurance during the 14-weeks training, representing $61.4 \%(\mathrm{p}<0.05)$ and $63.1 \%(\mathrm{p}<0.01)$ respectively.

\subsection{Effects of Training Program on Metabolic Complications of Obesity: Analyze of Correlations}

Table 6 brings back the correlation coefficients between the peak oxygen uptake, 
Table 5. Effects of exercise and diet on physical capacities in women.

\begin{tabular}{cccccc}
\hline Parameters & $\mathrm{T}(\mathrm{o})$ & $\mathrm{T}\left(7_{\text {weeks }}\right)$ & $\mathrm{T}(1$ 4weeks $)$ & \% change & $\mathrm{F}$ or S value; $\mathrm{p}$ \\
\hline $\mathrm{VO}_{2 \text { peak }}(\mathrm{ml} / \mathrm{kg} / \mathrm{min})$ & $35.26 \pm 3.95$ & $37.67 \pm 4.16$ & $42.23 \pm 6.57$ & +13.4 & $11.05 ;<0.001$ \\
$\mathrm{VO}_{2 \text { peak }}(\mathrm{l} / \mathrm{min})$ & $3.18 \pm 0.15$ & $3.30 \pm 0.21$ & $3.43 \pm 0.12$ & +8.0 & $6.17 ;<0.01$ \\
$\mathrm{VO}_{2 \text { peak }}(\mathrm{ml} / \mathrm{kg}$ LBM $/ \mathrm{min})$ & $39.18 \pm 2.76$ & $41.51 \pm 1.83$ & $45.27 \pm 2.14$ & +15.5 & $19.40 ;<0.001$ \\
Gait speed (m/min) & $72.3 \pm 2.5$ & $73.8 \pm 3.6$ & $76.2 \pm 3.1$ & +5.4 & $4.29 ;<0.05$ \\
& & Normal walking & & \\
Speed (m/s) & $1.32 \pm 0.08$ & $1.38 \pm 0.12$ & $1.53 \pm 0.06$ & +15.9 & $17.2 ;<0.001$ \\
Cadence (steps/min) & $119.0 \pm 8.6$ & $124.0 \pm 5.3$ & $130.8 \pm 8.5$ & +9.1 & $6.4 ;<0.01$ \\
Stride length (m) & $1.32 \pm 0.09$ & $1.40 \pm 0.06$ & $1.50 \pm 0.10$ & +13.6 & $11.99 ;<0.001$ \\
& & Fast walking & & \\
Speed (m/s) & $1.80 \pm 0.21$ & $1.93 \pm 0.15$ & $2.11 \pm 0.12$ & +17.2 & $9.56 ;<0.001$ \\
Cadence (steps/min) & $141.0 \pm 9.7$ & $146.4 \pm 8.1$ & $154.2 \pm 9.7$ & +9.2 & $5.54 ;<0.05$ \\
Stride length (m) & $1.51 \pm 0.12$ & $1.58 \pm 0.09$ & $1.78 \pm 0.07$ & +17.8 & $6.25 ;<0.01$ \\
Sit-up (n) & $10.1 \pm 3.5$ & $12.1 \pm 5.2$ & $15.3 \pm 3.3$ & +61.4 & $4.38 ;<0.05$ \\
IEE (n) & $6.5 \pm 3.1$ & $8.3 \pm 2.8$ & $10.6 \pm 2.4$ & +63.1 & $5.81 ;<0.01$ \\
\hline
\end{tabular}

Abbreviation: IEE, inflections-extensions of elbows.

Table 6. Coefficients of correlation between some blood lipoproteins and the peak oxygen uptake, percentage of visceral abdominal fat and waist circumference.

\begin{tabular}{|c|c|c|c|c|c|c|}
\hline & \multicolumn{2}{|c|}{$\mathrm{VO}_{2 \text { peak }}$} & \multicolumn{2}{|c|}{ VA fat } & \multicolumn{2}{|c|}{ WC } \\
\hline & $\mathrm{r}$ & $\mathrm{p}$ & $\mathrm{r}$ & $\mathrm{p}$ & $\mathrm{r}$ & $\mathrm{p}$ \\
\hline \multicolumn{7}{|l|}{ Before training } \\
\hline CHOL & -0.19 & 0.073 & 0.24 & 0.079 & 0.27 & 0.072 \\
\hline LDL-CHOL & -0.16 & 0.070 & 0.35 & 0.067 & 0.41 & 0.052 \\
\hline HDL-CHOL & -0.12 & 0.087 & 0.12 & 0.086 & 0.18 & 0.075 \\
\hline TG & -0.10 & 0.091 & -0.24 & 0.079 & -0.30 & 0.069 \\
\hline VLDL - TG & -0.14 & 0.082 & -0.29 & 0.072 & -0.34 & 0.064 \\
\hline \multicolumn{7}{|l|}{ After training } \\
\hline CHOL & -0.08 & 0.103 & 0.43 & 0.058 & 0.38 & 0.061 \\
\hline LDL-CHOL & -0.10 & 0.091 & $0.51^{*}$ & 0.045 & $0.52^{*}$ & 0.043 \\
\hline HDL-CHOL & -0.08 & 0.103 & 0.26 & 0.074 & 0.27 & 0.072 \\
\hline TG & -0.09 & 0.090 & -0.17 & 0.073 & -0.19 & 0.073 \\
\hline VLDL - TG & -0.05 & 0.124 & -0.11 & 0.089 & -0.08 & 0.103 \\
\hline
\end{tabular}

Abbreviations: CHOL, total cholesterol; LDL-CHOL, low density lipprotein-cholesterol; HDL-CHOL, high density lipoprotein-cholesterol; TG, triglycerides; VLDL-TG, very low density lipoprotein-triglycerides; ${ }^{*}, \mathrm{p}$ $<0.05$.

visceral abdominal fat, $\mathrm{WC}$, total fatty mass and some metabolic parameters concentrations noted before and after training program. 
A dissociation between of changes of peak oxygen uptake and metabolic improvements was observed. On the other hand, the reductions in LDL-cholesterol and total cholesterol concentrations were proportional to the reduction of percentage of visceral abdominal fat and waist circumference.

\section{Discussion}

Obesity in older adult women is a public health problem that challenges our health care, adapted physical activities and rehabilitation professionals, and health care delivery systems [32] [33]. But what happen for the young Congolese adult women? The principal findings of this study are that weight loss induced by exercise and low calorie diet based on Congolese meats decrease total and abdominal fat, improve plasma lipoprotein levels and ameliorate insulin sensitivity, and improve physical functional capacity.

\subsection{Physical Activity and Specific Dietary}

Debate continues among health professionals about whether a low-calorie diet low-or moderate-intensity aerobic exercise are a beneficial as more-vigorous exercise for reducing abdominal obesity, maximizing improvements in cardiovascular diseases (CVD) risk factors, decreasing insulin resistance that precedes and predicts the development of type 2 diabetes mellitus, and substantial improvements in plasma lipoproteins levels and four physical functions necessary in routine daily life.

In this study, even if our data do not rest one a nationally representative survey, our data indicate at the admission of training program that all women categorized have inactive. Other authors use additional step-count cutoff points to define physical activity (PA), stratifying individuals have "low active", "somewhat active", but "highly active" [34] [35]. Our findings show that our women had a very low level of PA in work (office, residence) and especially in leisures, so much so that categorized we them "sedentaries". This constitutes of not to doubt a major etiologic factor of the increase of weight, therefore of occurred of obesity because the relation between level of PA and BMI [36]. The low levels of PA in all 34 subjects from Brazzaville, city whose population (1,452,714 habitants) represents more than a third of that of Congo (4,826,212 habitants), might related to some aspects of their lifestyle, dietary habits, socioeconomic and environmental factors to increasing risk of adiposity in this population group. In fact, despite the several benefits on health associated with a physically activate lifestyle, there are high levels of inactivity across the supported social layers, with participation in PA declining significantly with age in both genders, particularly in females. However, the major factors are: 1) the expensive cost of a fitness session in the private fitness clubs (estimated to 10 USD per week, whereas the average wage of Congolese worker is 175 USD), 2) the scarcity and/or avaibility of public sports grounds, parks and facilities that are suitable to engage physical activities or sport. It is in this context that the town council of Brazzaville took a 
deliberation on the closing of Cornice Boulevard, skirting right bank of the Congo River on a distance of $9 \mathrm{~km}$ due southwest in order to promote PA, particularly the practice of jogging and muscular exercises.

Our subjects had $360 \mathrm{~min} / \mathrm{wk}$ during training program. The current guidelines from the American College of Sports Medicine that recommends moderate intensity PA of $>250 \mathrm{~min} / \mathrm{wk}$ has been associated with clinically significant weight loss [37]. These guidelines also showed a beneficial effect of moderate to vigorous exercise for $300 \mathrm{~min} / \mathrm{wk}$ compared with $150 \mathrm{~min} / \mathrm{wk}$ for reducing adiposity measures and body weight. However, so far, the effects of different weekly patterns of PA on weight loss are unknown. A recent randomized controlled trial of Madjd et al. [38] report that the frequency of moderate to vigorous PA during the week is also significant as the total volume of moderate to vigorous PA. In addition, this study examined the association between the frequency of PA throughout the week and weight loss in overweight and obese women.

The present study included a dietary intervention to achieve weight loss in our subjects. Concerning food intake measurements (Table 2), our daily energy intakes were lower than those reported by Mbemba et al. [39] among active Congolese women, $2080 \pm 520 \mathrm{kcal} / \mathrm{d}$. The lipid intakes were strongly recommended not to the level quantity but in their presentation in the energy intake because they have in more one less capacity of satiety. In addition, the food was rich in unsaturated fatty acids of vegetable origin; this fact, contrary to the saturated fatty acids, contribute to decrease the risk and to improve the glucose tolerance if the total fat content intake is not excessive (maximum $37 \%$ of total energy). As for monounsatured fatty acids (FA) and polyunsatured FA, they were brought by vegetable oils, respectively the nut or colza, soya, peanuts, palm and sunflower oils bought in the trade (traditional markets and supermarkets). The consumption of meat was rather significant at our subjects. Indeed, the meat is an average source of energy, provided by proteins and lipids. However, the energy value of meat is rather variable and depends on its content of lipids, the proteins remaining always rather constant. In our study, the consumed aliments, not frozen for the majority, were: for the red meat, ox and sheep; for the white meat, chicken, turkey, duck and pig; and finally for the black meat or game meat, blue duiker (Cephalophus monticola), bushbuck (Tradelaphus scriptus) and Peter's duiker (Cephalophus callipygus). The frozen red meat was strongly disadvised at our subjects during the study by supporting us on the results of the study of Bauchard et al. [40]. These authors, in a study investigating the effects on lipids meat and FA of extruded linseed (high in $n-3$ polyunsatured FA) alone or extruded rapeseed (high in n-6 and n-3 and 18: $1 \mathrm{n}-9$ polyunsaturated FA) in association or not with antioxidants in dairy cows, report that increased uptake of n-3 polyunsaturated FA by cattle with flax diet would stimulate lipoperoxidation in his entire body, altering the health of meats for the consumer.

The fish and other cold-blooded animals to consume whose proteins are as of good quality as those of the meat, they were fresh water and sea water fishes. 
They were represented by sea-breams, plate, catfish or silure (Clarias), and sometimes dzombo (Protepterus $s p$ ). By opportunity, the aliments could comprise shellfish (crayfish, crabs, shrimps), molluscs (snail Achatina achatina). In the same way, reptilians' meats (dwarf crocodile or Osteolacmus tetrapsus, tortoise) were found, those having probably the same nutritional characteristics as thin fishes [41] [42]. As for the edible insects and larvae, one found termites, crickets and caterpillars [very rich in proteins (10 to $50 \mathrm{~g} / 100 \mathrm{~g}$ ), lipids (approximately $10 \mathrm{~g} / 100 \mathrm{~g}$ ) and $\mathrm{B}$ vitamins], which were inserted in the total food availability, fresh or dried.

The food consumption containing of complex carbohydrates was favoured for at least two reasons: they are a good source of starch on the one hand, and they are often rich in micronutrients (trace elements and vitamins) and fibers on the other hand. It acted: products containing cereals (wholewheat bread, brown rice, spaghetti, and oats); roots and tubers; starch-based ones [green plantain banana, yam, flour of cassava (or "foufou"), "chikwangue", fresh cassava, sweet potato and taro], and leguminous plants (dry haricot bean, pea, soya, ...). The food based on complete feedingstuffs of vegetable origin, as for it, was most effective, which joined various studies [42] [43]. This type of food allows indeed a drastic reduction in glycemia and weight loss [42]. For low energy intakes, the consumption of fruits and vegetables were mainly related to: oranges, mangos, potatoes, Gnetum africanum, marrow sheets (Coccinia barteri), sorrel (Hibiscus sabderifa), wild stems of yams (Dioscorea schimperiana), asparaguses (Lasccorperma secundiflorum), endives (Brassica-spp), sweet potato sheets and other vegetables (spinaches, mushrooms ...). Lastly, liquid intakes (mineral water of Congo) and consumption of rich foods in carbohydrates (whole grains, fruits) and proteins (soy products, egg white, lean meats) were found in sufficient quantities.

Concerning the modes of culinary preparation, the red meats were prepared by direct cooking with water, sauce or cooked with ember. The fresh water fish and white meats were often prepared with water or were cooked with choked in sheets of marantacees ("maboke" in local language).

\subsection{Body Composition and Fat Distribution}

The reduction of weight loss, $12.2 \pm 5.6 \mathrm{~kg}(16 \%)$ in this study (Table 3 ), is higher than that reported in a Cameroonese study bearing on the 3 months impact of practice of the physical activities among obese women: $3.3 \%$ in the age bracket $29-34$ years, $3.8 \%$ at $35-39$ years and $3.7 \%$ at $40-44$ years [44]. However, these women were not subjected to a hypocalorie food regimen. In the randomized study of Ross et al. [45], comparing the effects of a calorie restriction associated 4 weeks of physical exercises of intensity of moderate to intensive in Canadian women of comparable age (24 - 47 years) and average weight 90.3 $\mathrm{kg}$, weight loss is lower than ours: $9.3 \pm 0.8 \mathrm{~kg}(-9.3 \%)$. These changes can explained by the methodological procedures [particularly volume of training, con- 
tents of the sessions and sample size ( 9 women in the Canadian study)]. Among older women (57.7 years on average) and postmenopausal, Nicklas et al. [46] report an average weight loss of $12.1 \pm 4.5 \mathrm{~kg}(-13 \%)$ during a program of 20 weeks of PA combined with a hypocalorie regimen. However, the calorie deficits of those women were adjusted to $2800 \mathrm{kcal} / \mathrm{wk}$ ( $\approx 400 \mathrm{kcal} / \mathrm{d})$, but no women was provided with $<1100 \mathrm{kcal} / \mathrm{d}$. In addition, exercising was discontinued within the first months because of time restraints or chronic, reoccurring insult.

Our physical work program combined with low calorie diet also produced statistically significant changes at 14 weeks in total fat mass $(-26.4 \% ; \mathrm{p}<0.001)$ and body fat $(-12.1 \% ; \mathrm{p}<0.01)$. Weight, TFM and body fat changes was more high in the 7- to 14 -weeks period: $7.5 \pm 4.3 \mathrm{~kg}$ vs. $4.7 \pm 2.1 \mathrm{~kg}$ in the 0 - to 7 -weeks period for weight, $18.6 \pm 2.1 \mathrm{~kg}$ vs. $6.5 \pm 1.7 \mathrm{~kg}$ in the 0 - to 7 -weeks period ( $\mathrm{p}<$ 0.01 ) for TFM, and $6.5 \%$ vs. $5.2 \%$ in the 0 - to 7 -weeks period for TLBM ( $p>$ 0.05 ). These observations join other studies which highlight a higher loss of abdominal fat with a more intensive physical exercise [23] [47], probably related to a more significant total energy expenditure. These findings are in agreement with other carryforwards were significant differences, shown for TFM, body fat and TLBM [48] [49]. However, these results are contrary with those of Saygin and Öztürk [50], which does not observe a significant decrease on the level of TFM, body fat and lean body mass during a program of 12 weeks of aerobic exercises in the absence of follow-up of hypocalorie food regimen.

\subsection{Exercise and Diet-Induced Changes in Lipoproteins}

The weight loss resulted in significant decreases at 14 weeks of training program in fasting plasma glucose $(-13 \% ; \mathrm{p}<0.05)$ and fasting serum insulin $(-60.9 \% ; \mathrm{p}$ $<0.05$ ), correlated with changes of insulin sensitivity (decrease HOMA-IR index of $64.7 \%$; $\mathrm{p}<0.001$ ) (Table 4). Insulin resistance of obesity is characterized by skeletal muscle glucose uptake and, more specifically, by reduced glycogen storage [8]. In addition, in a study of Petersen et al. [51] elevated levels of intramyocellular triglyceride (IMTG) have been found in young, lean, insulin-resistant offspring of patients with type 2 diabetes mellitus, suggesting a role for defects in lipid metabolism as a cause of insulin resistance. These metabolic defects in obesity content are strongly associated with increased visceral fat. The practice of physical exercises combined with a food hypocaloric regimen, thus produced of beneficial effects on tissue sensitivity to insulin, like brought it back other studies [52] [53]. The mechanisms by which this improvement of insulin sensitivity linked are dependent of a stimulation of insulin, and in addition with the increase in the metabolism of FA in the skeletal muscle. Indeed, during fasting conditions, oxidation of FA is generally considered to principal be the substrate of skeletal muscle. Numerous biochemical alterations of skeletal muscle and insulin signaling pathways cuts had been identified in relation to insulin-resistant glucose metabolism, and have well improvements after weight loss induced by training program in obese individuals [54] [55]. In addition, study of 
Laaksonen et al. [55] shown that weight loss improves not only insulin sensitivity, or also increases adipose tissue blood flow. However, extravascular or interstitial fluid volume in relation to insulin physiology has not been studied in this survey. In a previous study, we examine among obese women subjected to a training program combined with low calorie diet whether patterns of muscle enzyme activity and some skeletal muscle markers are interrelated to the phenotype in insulin resistance and glucose metabolism.

Lastly, it was observed at 14 weeks of training program reductions in the plasma cholesterol concentrations $(-12.2 \%$; $\mathrm{p}<0.01)$, LDL-cholesterol $(-20.3 \%$; $\mathrm{p}<0.05)$, triglycerides $(-92.8 \% ; \mathrm{p}<0.001)$, and VLDL-triglycerides $(-17.5 \% ; \mathrm{p}<$ $0.05)$. The more the sensitivity is improved, the more the reduction in the plasma levels of cholesterol and the increase in HDL-cholesterol concentrations are significant, and $\mathrm{VO}_{2 \text { peak }}$ increase (Table 6). Our results consolidate those of Després et al. [56], Lawani et al. [57] on the fact that the mobilization of abdominal fat constitutes a significant component of the metabolic adaptations to aerobic training. These authors observed metabolic improvements, including several significant changes in the concentrations of plasma lipoproteins in a group of premenopausal obese women subjected to a physical work program comprising 4 to 5 sessions of exercises per week, each of one duration of $90 \mathrm{~min}$, and this for one 14 month period. Moreover, the improvement of insulin sensitivity seems to determine to a certain extent the observed changes in the transport of blood lipids in response to exercise training.

\subsection{Function Capacity}

The results on aerobic capacity (Table 5) show that peak oxygen consumption values expressed as $\mathrm{ml} / \mathrm{kg} / \mathrm{min}$ and $\mathrm{ml} / \mathrm{kgLBM} / \mathrm{min}$ significantly increased at 14 weeks of training program, respectively $42.23 \pm 6.57 \mathrm{ml} / \mathrm{kg} / \mathrm{min}$ vs $35.26 \pm 3.95$ $\mathrm{ml} / \mathrm{kg} / \mathrm{min}(+13.4 \% ; \mathrm{p}<0.001)$ and $45.27 \pm 2.14 \mathrm{ml} / \mathrm{kgLBM} / \mathrm{min}$ vs $39.12 \pm 2.76$ $\mathrm{ml} / \mathrm{kgLBM} / \mathrm{min}(+15.5 \% ; \mathrm{p}<0.001)$. Obesity is accompanied by an increased metabolic request and involves a ventilatory work requiring a larger energy [58]. Another authors evoked the endocrinian fat tissue role with its adipokines who produce pro-inflammatory mediators (IL-6, CRP) [59] [60]. This systemic ignition could then affect the respiratory tracts and support the bronchial obstruction. Consequently, the improvements that were seen in our data among the participants of this study cuts significant implications for the ability of obese women to maintain to their health. The relative $\mathrm{VO}_{2 \text { peak }}$ to body weight is the standard measure for assessing cardiovascular fitness, and significant $\mathrm{VO}_{2 \text { peak }}$ is for assessing the ability to perform activities, this require movement of increased body weight. Donnelly et al. [47] reported also changes in oxygen consumption associated with a low calorie diet and physical training in obese females, estimated to $9 \%$ increase over the baseline values. Muscular training in addition to endurance may simply reflect additional benefits of increased volume of exercise. In addition, the study of the correlations between $\mathrm{VO}_{\text {2peak }}$ and lipoproteins 
concentrations (Table 6) show that the improvement of the metabolic profile (serum lipoproteins) has as a consequence the improvement of cardiorespiratory condition of our subjects. Our results suggest that the energy expenditure associated with physical training according to our protocol represents in oneself a significant component of observed metabolic adaptations. In addition, speed and stride length are also increased at 14 weeks of normal training program during gait walking and fast walking. Our observations join those of other authors having studied the influence of the programs of weight loss induced by physical exercises practice combined with a calorie restriction. For example, the study of Villareal et al. [61] brings back an improvement of $\mathrm{VO}_{2 \text { peak }}$ (in $\mathrm{ml} / \mathrm{kg} / \mathrm{min}$ ) of $2.8 \%$ in 6 months and $3.1 \%$ in one year in obese older adults.

With regard to functional capacities such as speed and stride length gait, we also noted an improvement of performances (Table 5). However, even if the studies relating to these parameters are rare, our observations join those of $\mathrm{Pa}$ taky et al. [62]. An explanation for that might be the decrease of energy expenditure during walking and improvement of mechanical efficiency. Muscular endurance performances showed an increase over the baseline values. We think that improvement of muscular endurance may be attributed to increase capacity for the uptake and transport of fatty acids with the muscle cell and a capacity of their oxidation within the mitochondria.

The strength of our study is the first in Central Africa included obese Bantu women, the comprehensive diet based on African aliments, the abdominal parameters of body composition, the biochemical indicators of cardiometabolic disease risk, and the use of objective measures of physical fitness. However, interpretation of our results must take account of two limitations. A first limitation is that our sample size is small. Clearly, further studies using larger cohorts of subjects treated with different types of diets and exercise regimens are required. Second, the determination of abdominal fat was based on the bioelectrical impedance analysis. It would have been judicious to use dual-energy X-ray absorptiometry (DXA), technique nonavailable in Congo. However, a study of Pineau and Frey showed the reliability of impedancemetry, which reduces gap error to \pm $2 \%[63]$.

\section{Conclusion}

Our findings suggest that a combination of weight loss and low-calorie diet based on Congolese aliments, and exercise significantly reduced the total fat mass and quantity of abdominal fat, the sensitivity to insulin improves substantially and reduces the plasma LDL-cholesterol and total cholesterol, triglycerides concentrations, and improves functional physical capacities (speed, cadence and stride length during walking; muscular endurance). Therefore, weight loss combined with regular exercise and low-calorie diet may be beneficial in helping obese African young adult women maintain their health through a well-being and healthy lifestyle. In addition, our study underlines the importance of assessing 
obese patients' relating physical problems at an early stage of obesity in order to focus exercise regimens and appropriate low-calorie diet and promote health behaviors.

\section{Author Contributions}

MJGA, PTB and MA conceived and designed the experiments with the help from MVG and MRLS carried out the experiments with the help from students and laboratory technicians. EMLE acted as a physician of the project. MJGA drafted the manuscript. Analysis was conducted by MVG, MRLS, and NMC together with students and technicians. MA and PTB refined the study design and contributed to data interpretation. All authors critically read/revised and approved the final manuscript.

\section{Acknowledgements}

The authors express their extreme gratitude for the clinical biologists and technicians at Biomedical Analyses Center, Brazzaville. We all so would like to particularly thank all the participants who volunteered for this study, as well as the coach of fitness club, dietitians, exercise physiologists, and other research staff of Laboratory of Sports Biosciences.

\section{Conflicts of Interest}

The authors declare no conflict of interest.

\section{References}

[1] Delpeuch, F. and Maire, B. (1997) Obésité et développement des pays du sud. Médecine Tropicale, 57, 380-388.

[2] Popkin, B.M. (1994) Nutrition Transition in Low-Income Countries: An Emerging Crisis. Nutrition Reviews, 52, 285-298. https://doi.org/10.1111/j.1753-4887.1994.tb01460.x

[3] WHO (2018) Atlas of African Health Statistics 2018. Universal Health Coverage and the Sustainable Development Goals in the WHO African Region. WHO Office for Africa, Brazzaville.

[4] Harter, P. (2004) Mauritania's “Wife-Fattening” Farm. BBC. http://news.bbc.co.uk/1/hl/3429903.stm

[5] Haffner, S.M. (2007) Abdominal Adiposity and Cardiometabolic Risk: Do We Have All the Answers? The American Journal of Medicine, 120, S10-S16. https://doi.org/10.1016/j.amjmed.2007.06.006

[6] Olefsky, J.M. (1976) Decreased Insulin Binding to Adipocytes and Monocytes from Obese Subjects. The Journal of Clinical Investigation, 57, 1165-1172. https://doi.org/10.1172/JCI108384

[7] Cooper, S., Amoah, A.G. and Mensah, G.A. (2003) High Blood Pressure: The Foundation for Epidemic Cardiovascular Disease in African Populations. Ethnicity \& Disease, 12, S49-S52.

[8] Simoneau, J.A., Colberg, S.R., Thate, F.L. and Kelley, D.E. (1995) Skeletal Muscle Glycolytic and Oxidative Enzyme Capacities Are Determinants of Insulin Sensitivity 
and Muscle Composition in Obese Women. FASEBJ, 9, 273-278. https://doi.org/10.1096/fasebj.9.2.7781930

[9] Lai, P.P., Leung, A.K., Li, A.N. and Zhang, M. (2008) Three-Dimensional Gait Analysis of Obese Adults. Clinical Biomechanics, 23, S2-S6.

https://doi.org/10.1016/j.clinbiomech.2008.02.004

[10] Segal, N.A., Yack, H.J. and Khole, P. (2009) Weight, Rather than Obesity Distribution, Explains Peak External Knee Adduction Moment during Level Gait. American Journal of Physical Medicine \& Rehabilitation, 88, 180-188. https://doi.org/10.1097/PHM.0b013e318198b51b

[11] Gilleard, W. and Smith, T. (2007) Effect of Obesity on Posture and Hip Joint Moments during a Standing Task, and Trunk forward Flexion Motion. International Journal of Obesity, 31, 267-271. https://doi.org/10.1038/sj.ijo.0803430

[12] Greve, J., Alonso, A., Bordini, A.C. and Camanho, G.L. (2007) Correlation between Body Mass Index and Postural Balance. Clinics (Sao Paulo), 62, 717-720. https://doi.org/10.1590/S1807-59322007000600010

[13] Corbeil, P., Simoneau, M., Rancourt, D., Tremblay, A. and Teasdale, N. (2001) Increased Risk for Falling Associated with Obesity: Mathematical Modeling of Postural Control. IEEE Transactions on Neural Systems and Rehabilitation Engineering, 9, 126-136. https://doi.org/10.1109/7333.928572

[14] Wee, C.C., Huskey, K.W., Ngo, L.H., et al. (2011) Obesity, Race, and Risk for Death or Functional Decline among Medicare Beneficiaries: A Cohort Study. Annals of Internal Medicine, 154, 645-655. https://doi.org/10.7326/0003-4819-154-10-201105170-00003

[15] de Souza, S.A., Faintuch, J., Valezi, A.C., et al. (2005) Gait Cinematic Analysis in Morbiet by Obese Patients. Obesity Surgery, 15, 1238-1242. https://doi.org/10.1381/096089205774512627

[16] Singh, D., Park, W., Levy, M.S. and Jung, E.S. (2009) The Effects of Obesity and Standing Time on Postural Sway during Prolonged Quiet Standing. Ergonomics, 52, 977-986. https://doi.org/10.1080/00140130902777636

[17] Mc Tiernan, A., Sorensen, B., Irwin, M.L., et al. (2007) Exercise Effect on Weight and Body Fat in Men and Women. Obesity (Silver Spring), 15, 1496-1512. https://doi.org/10.1038/oby.2007.178

[18] Jokicic, J.M., Clark, K., Coleman, E., et al. (2001) American College of Sports Medicine Position Stand: Appropriate Intervention Strategies for Weight Loss and Prevention of Weight Regain for Adults. Medicine \& Science in Sports \& Exercise, 33, 2145-2156. https://doi.org/10.1097/00005768-200112000-00026

[19] Kusuayi, G.M., Bofosa, T.L., Kiana, N.N., Muela, N.D., Miangindula, B. and Nkiama, C.E. (2015) Effets des exercices physiques de l'endurance aérobies et de renforcement musculaire sur la composition corporelle des femmes obèses. Annals of African Medicine, 8, 2142-2148.

[20] Lathan, M.C. (1979) Nutrition humaine en Afrique tropicale. FAO, Rome.

[21] Mbemba, F. (1986) Mise au point et validation d'une méthodologie d'enquêtes alimentaires à l'usage du Congo [Thèse de doctorat non publiée]. Université de Nancy-I, Nancy.

[22] Souci, S.W., Fachman, W. and Kraut, H. (1994) Food Composition and Nutrition Tables. 5th Edition, Medpharm Scientific Publisher, CRC Press, Stuttgart.

[23] Redman, L.M., Heilbronn, L.K., Martin, C.K., Alfonso, A., Smith, S.R. and Ravissin, E. (2007) Effect of Calorie Restriction with or without Exercise on Body Composi- 
tion and Fat Distribution. The Journal of Clinical Endocrinology \& Metabolism, 92, 865-872. https://doi.org/10.1210/jc.2006-2184

[24] Lohman, T.G., Roche, A.F. and Martello, R. (Eds.) (1998) Anthropometric Standardization Reference Manual. Human Kinetics Books, Chicago.

[25] Houtkooper, L.B., Lohman, T.G., Going, S.B. and Howell, W.H. (1996) Why Bioelectrical Impedance Analysis Should Be Used for Estimating Adiposity. Annals of Clinical Nutrition, 64, 436S-448S. https://doi.org/10.1093/ajcn/64.3.436S

[26] Donnelly, J.E. (1987) Microcomputer Control of Graded Exercise Testing and Determination of Oxygen Consumption. In: Donnelly, J.E., Ed., Using Microcomputers in Physical Education and the Sports Sciences, Human Kinetics Publishers, Champaign, 169-190.

[27] Peters, D.M., Fritz, S.L. and Krotish, D.E. (2013). Assessing the Reliability and Validity of a Shorter Walk Test Compared with the 10-Meter Walk Test for Measurements of Gait Speed in Healthy, Older Adults. Journal of Geriatric Physical Therapy, 36, 24-30. https://doi.org/10.1519/JPT.0b013e318248e20d

[28] Thomas, E.L., Collins, E.L., McCarthy, J., Fritzpatrick, J., Durighel, G., Goldstone, A.P. and Bell, J.D. (2010) Estimation of Abdominal Fat by Bioelectrical Impedance: the Validity of the VisCan Measurement System in Comparison with MRI. European Journal of Clinical Nutrition, 64, 525-533. https://doi.org/10.1038/ejcn.2010.18

[29] ESH/ESC (2007) ESH Task Force for the Management of Arterial Hypertension of the European Society of Hypertension (ESH) and European Society of Cardiology (ESC). 2007 Guidelines for the Management of Arterial Hypertension. Journal of Hypertension, 25, 1005-1087. https://doi.org/10.1097/HJH.0b013e3282f0580f

[30] WHO (1996) WHO Scientific Group on Research on the Menopause in the 1990s. WHO Technical Report Series 866, Geneva, 1-106.

[31] Beck, A.T. and Beck, R.W. (1972) Screening Depressed Patients in Family Practice. A Rapid Technic. Postgraduate Medicine, 52, 81-85. https://doi.org/10.1080/00325481.1972.11713319

[32] Villareal, D.T., Apovian, C.M., Kushner, R.F. and Klein, S. (2005) Obesity in Older Adults: Technical Review and Position Statement of the American Society for $\mathrm{Nu}$ trition and NAASO, the Obesity Society. American Journal of Clinical Nutrition, 82, 923-934. https://doi.org/10.1093/ajcn/82.5.923

[33] Lapane, K.L. and Resnik, L. (2005) Obesity in Nursing Homes: An Escalating Problem. Journal of the American Geriatrics Society, 53, 1386-1391.

https://doi.org/10.1111/j.1532-5415.2005.53420.x

[34] Warburton, D.E., Charlesworth, S., Ivey, A., Nettlefold, L. and Bredin, S. (2010) A Systematic Review of the Evidence for Canada's Physical Activity Guidelines for Adults. International Journal of Behavioral Nutrition and Physical Activity, 7, 39. https://doi.org/10.1186/1479-5868-7-39

[35] Ainsworth, B.E., Haskell, W.L., Whitt, M.C., Irwin, M.L., Swartz, A.M., Strath, S.J., et al. (2000) Compendium of Physical Activities: An Update of Activity Codes and MET Intensities. Medicine \& Science in Sports \& Exercise, 32, s498-s516. https://doi.org/10.1097/00005768-200009001-00009

[36] Westerterp, K.R. (1999) Obesity and Physical Activity. International Journal of Obesity, 23, 59-64. https://doi.org/10.1038/sj.ijo.0800797

[37] Donnelly, J.E., Smith, B., Jacobsen, D.J., Kirk, E., Dubose, K., Hyder, M., et al. (2004) The Role of Exercise of Weight Loss and Maintenance. Best Practice \& Research Clinical Gastroenterology, 18, 1009-1029. 
https://doi.org/10.1016/S1521-6918(04)00083-6

[38] Madjd, A., Taylor, M.A., Neek, L.S., Delavari, A., Malekzadeh, R., Macdonald, I.A., et al. (2016) Effect of Weekly Physical Activity Frequency on Weight Loss in Healthy Overweight and Obese Women Attending a Weight Loss Program: A Randomized Controlled Trial. American Journal of Clinical Nutrition, 104, 1202-1208. https://doi.org/10.3945/ajcn.116.136408

[39] Mbemba, F., Bantsimba, M., Massamba, A. and Senga, P. (2005) Alimentation d'une population adulte active à Brazzaville (Congo). Médecine \& Nutrition, 41, 183-188. https://doi.org/10.1051/mnut/2005414183

[40] Bauchard, D., Gobert, M., Habeanu, M., Parafita, E., Gruffat, D. and Durand, D. (2010) Influence des acides gras polyinsaturés n-3 et des antioxydants alimentaires sur les acides gras de la viande et la lipoperoxydation chez le bovin en finition. Cahiers de Nutrition et de Diététique, 45, 301-309.

https://doi.org/10.1016/j.cnd.2010.06.002

[41] Fossati, P., Romon, M. and Sagnier, N.C. (1980) Enquête alimentaire et cahier diététique. Nouvelle Presse Médicale, Paris.

[42] Bounaud, V., Moreau, F. and Garnaud, A.T. (2015) Nutrition, maladies chroniques, obésité, activités physiques. Synthèse documentaire réalisée dans le cadre de la mise en place des plateformes. ORS Rapport No. 167, Poitiers.

[43] Roberts, S.B. (2000) Regulation of Energy Intake in Relation to Metabolic State and Nutritional Status. European Journal of Clinical Nutrition, 54, S64-S69.

https://doi.org/10.1038/sj.ejcn.1601027

[44] Guessogo, W.R., Assomo Ndemba, P.B., Temfomo, A., Ebal Menye, E., Mpende Alamba, M., Tadjore Ndjock, M., et al. (2016) Effets de 3 mois de pratique régulière des activités physiques et sportives de maintien sur la composition corporelle et les paramètres psychologiques chez des femmes obèses ou en surpoids au Cameroun. Ann Sciences Santé, 1, 20-27.

[45] Ross, R., Léger, L., Marliss, E.B., Morris, D.V. and Gougeon, R. (1991) Adipose Tissue Distribution Changes during Rapid Weight Loss in Obese Adults. International Journal of Obesity, 15, 733-739.

[46] Nicklas, B.J., Wang, X., You, T., Lyles, M.F., Demons, J., Easter, L., Berry, M.J., et al. (2009) Effects of Exercise Intensity on Abdominal Fat Loss during Calorie Restriction in Overweight and Obese Postmenopausal Women: A Randomized, Controlled Trial. American Journal of Clinical Nutrition, 89, 1043-1052. https://doi.org/10.3945/ajen.2008.26938

[47] Donnelly, J.E., Pronk, N.P., Jacobsen, D.J., Pronk, S.J. and Jakicic, J.M. (1991) Effects of a Very-Low-Calorie Diet and Physical-Training Regimens on Body Composition and Resting Metabolic Rate in Obese Females. American Journal of Clinical Nutrition, 54, 56-61. https://doi.org/10.1093/ajcn/54.1.56

[48] Hammer, R.L., Barrier, C.A., Roundy, E.S., Bradford, J.M. and Fisher, A.G. (1989) Calorie-Restricted Low-Fat Diet and Exercise in Obese Women. American Journal of Clinical Nutrition, 49, 77-85. https://doi.org/10.1093/ajcn/49.1.77

[49] Pavlou, K.N., Steffe, W.P., Lerman, R.H. and Burrows, B.A. (1985) Effects of Dieting and Exercise on Lean Body Mass, Oxygen Uptake, and Strength. Medicine \& Science in Sports \& Exercise, 17, 466-471. https://doi.org/10.1249/00005768-198508000-00011

[50] Saygin, Ö. and Öztürk, M.A. (2011) The Effect of Twelve Week Aerobic Exercise Program on Health Related Physical Fitness Components and Blood Lipids in Obese Girls. African Journal of Pharmacy and Pharmacology, 5, 1441-1445. 
https://doi.org/10.5897/AJPP11.114

[51] Petersen, K.F., Dufour, S. and Shulman, G.I. (2005) Decreased Insulin Stimulated ATP Synthesis and Phosphate Transport in Muscle of Insulin-Resistant Offspring of Type 2 Diabetic Parents. PLoS Medicine, 2, e233-e238. https://doi.org/10.1371/journal.pmed.0020233

[52] Rabol, R., Svendsen, P.F., Skovbro, M., Boushel, R., Haugaard, S.B., Schjerling, P., et al. (2009) Reduced Skeletal Muscle Mitochondrial Respiration and Improved Glucose Metabolism in Nondiabetic Obese Women during a Very Low Calorie Dietary Intervention Leading to Rapid Weight Loss. Metabolism: Clinical and Experimental, 58, 1145-1152. https://doi.org/10.1016/j.metabol.2009.03.014

[53] Kern, P.A., Simsolo, B. and Fournier, M. (1999) Effect of Weight Loss on Muscle Fiber Type, Fiber Size, Capillarity, and Succinate Dehydrogenase Activity in $\mathrm{Hu}$ mans. The Journal of Clinical Endocrinology \& Metabolism, 84, 4185-4190. https://doi.org/10.1210/jc.84.11.4185

[54] Toledo, F.G., Menshikova, E.V., Azuma, K., et al. (2008) Mitochondrial Capacity in Skeletal Muscle Is Not Stimulated by Weight Loss Despite Increases in Insulin Action and Decreases in Intramyocellular Lipid Content. Diabetes, 57, 987-994. https://doi.org/10.2337/db07-1429

[55] Laaksonen, D.E., Nuutinen, J., Lahtinen, J., Rissanen, A. and Niskanen, L.K. (2003) Changes in Abdominal Subcutaneous Fat Water Content with Rapid Weight Loss and Long-Term Weight Maintenance in Abdominally Obese Men and Women. International Journal of Obesity, 27, 677-683. https://doi.org/10.1038/sj.ijo.0802296

[56] Després, J.P., Tremblay, A., Nadeau, A. and Bouchard, C. (1988) Physical Training and Changes in Regional Adipose Tissue Distribution. Acta Medica Scandinavica, 723, 205-212. https://doi.org/10.1111/j.0954-6820.1987.tb05945.x

[57] Lawani, M.M., Akplogan, B. and Yessoufou, L. (2005) Effet de l'entraînement aérobie de courte durée sur les cholestérols et triglycérides sanguins chez des femmes béninoises obèses. Rev CAMES-Série A, 3, 57-61.

[58] Piper, A.J. and Grunstein, R.R. (2010) Bigbreathing. Journal of Applied Physiology, 108, 199-205. https://doi.org/10.1152/japplphysiol.00713.2009

[59] Lessard, A., Almeras, N., Turcotte, H., Tremblay, A., Després, J. and Boulet, L.P. (2011) Adiposity and Pulmonary Function: Relationship with Body Fat Distribution and Systemic Inflammation. Clinical and Investigative Medicine, 34, E64-E70. https://doi.org/10.25011/cim.v34i1.15102

[60] Pou, K.M., Massaro, T.M., Hoffman, U., Vasan, R.S., Maurovich-Horvat, P., Larson, M.G., et al. (2007) Visceral and Subcutaneous Adipose Tissue Volumes Are Cross-Sectionally Related to Inarkers of Inflammation and Oxidative Stress: Framingham Heart Study. Circulation, 116, 1234-1241. https://doi.org/10.1161/CIRCULATIONAHA.107.710509

[61] Villareal, D.T., Chode, S., Parimi, N., Sinacore, D.R., Hilton, T., Armanento-Villareal, R., et al. (2011) Weight Loss, Exercise, or Both and Physical Function in Obese Older Adults. The New England Journal of Medicine, 364, 1218-1229. https://doi.org/10.1056/NEJMoa1008234

[62] Pataky, Z., Armand, S., Müller-Pinget, S., Golay, A. and Allet, L. (2014) Effects of Obesity on Functional Capacity. Obesity, 22, 56-62. https://doi.org/10.1002/oby.20514

[63] Pineau, J.C. and Frey, A. (2014) Comparaison de la composition corporelle obtenue par bio-impédance et par absorptiométrie biphotonique chez des sportifs de haut niveau. Science \& Sports, 29, 164-167. https://doi.org/10.1016/j.scispo.2014.03.001 